\title{
The Influence Law of Multi-point Cumulative Blasting in Slope
}

\author{
Liu Han ${ }^{1}$, Jisen Shu ${ }^{1 *}$, Yanjun $\mathrm{He}^{2}$, Tao Chen ${ }^{1}$, Changchao She ${ }^{3}$ \\ 1. Shool of Mines, China University of Mining \& Technology, Xuzhou 221116, China; \\ 2. Mining Research Institute, Inner Mongolia University of Science and Technology, Baotou 014010, \\ China; \\ 3. Shenhua Beidian Shengli Energy Co., Ltd., Xilinhot 026000, China
}

Received: November 28. Revised: December 25, 2020. Accepted: December 28, 2020.

\begin{abstract}
In order to study the cumulative blasting stress wave produced by the vibration of soft rock slope, the deformation regularity of the influence of blasting, caused by the horizontal and axial acceleration along with other additional stress waves were analyzed. The vibration displacement formula along with the vibration source stress wave superimposed model were established. The research also deduced the deformation rule for the gangue slope of Lijiahao Coal Mines as a vibration signal recorder was used to collect the blast vibration wave and the simulated analysis of displacement monitoring profile of the $X$ and $Y$ displacement rule under the influence of blast vibration were obtained. The results indicate that with the increase of the shot point distance, the displacement in the $Y$ direction shows a logarithmic decline rule while the change in displacement of the $X$ direction is small. The result also shows that the greater the initiation of multipoint shot firing, the greater the slope deformation and displacement of the rock mass and as a result multipoint non-simultaneous blasting and control detonation time difference, can effectively reduce the effects of vibration on the slope deformation.
\end{abstract}

Keywords - Signal, Signal Processing, Applied Signal processing, Blast vibration, Multipoint blasting, Slope, Accumulative Deformation.

\section{INTRODUCTION}

$\mathrm{B}$ lasting vibration is a nature kind of common dynamic load (Yang et al., 2013), as the vibration load is in the form of stress wave propagation in the rock mass (Chang et al., 2011). For the stability of slope of structural plane, the controlling effect of blast vibration is significant and the loss mechanism in addition to the stress load caused by vibration on the structure surface shows that the plane structural damage accumulates and its shear strength weakens (Chen et al., 2009). Dump slope is a common slope (Han et al., 2015; Han et al., 2014), due to the low stiffness and strong elastic-plastic material of it rock mass with more obvious deformation occurring under external stress phenomenon (Exadaktylos et al., 2008). When deformation operations continued on the slope, it produces cumulative deformation, and adverse effects on its structural integrity and stability.

Due to the poor lithology of the original formation, the overall strength of the artificial slope formed by coal mine stripping is also low. Cover stripping or coal mining operations require frequent loose blasting. The vibration energy generated by blasting directly affects the deformation and stability of soft rock slopes (Gao \& Fan, 2010; Jeremy, 2014). At present, some mining areas have caused slopes caused by blasting operations. Deformation and landslide accidents. Wu et al.,(2020) the stability of the slope under the high vibration limit blasting is evaluated by the method of minimum blasting strength under the bench. On this basis, Wu et al., (2020) further studied the mechanical cumulative damage model of slope fault fracture zone under the cumulative action of blasting vibration. In addition to blasting vibration, the load generated by the earthquake can also induce slope landslides. For example, the Wenchuan earthquake in Sichuan, China in 2008, caused a large number of casualties and economic and property losses, and also caused a large number of landslides (Yin et al., 2011).

After the earthquake, many experts and scholars have carried out a detailed study. Fan et al. (2018) has learned lessons from the 2008 Wenchuan earthquake and its consequences, and made clear that the future research focus is to explore the trigger and the mechanism of coseismic landslides, their rainfall induced reactivation, the generation of debris flow, the evolution of its controlling factors, and the long-term role of earthquakes in terrain shaping.

At present, for the analysis of soft rock slope stability and deformation law theory (Yoon et al., 2002; Mihaela et al., 2011), proposed the soil stability table (Taylor, 1937), and applied it to soil slope stability judgment. Based on Mohr coulomb criterion and Hoek and Bray (Hoek, 1977) stability decision table, laid a solid foundation for the next step of 
research regarding soft rock slope stability evaluation. So far, derived by the limit equilibrium method of slope stability calculation methods (such as Fellenius, Janbu, Spencer) and finite element method (FEM) has been widely applied to the quantitative calculation of slope stability (Alejano et al., 2011), and to form the corresponding numerical simulation software, the results greatly enriched understanding the process of soft rock slope deformation and stability evaluation methods and analysis (Chen \& Shao, 1987). For example, Ronevi et al., (2018) Used computer code to realize the introduction of a virtual spring with zero stiffness in the free vibration analysis of The Euler Bernoulli beam, which improves the reliability of the calculation. Jauhari (2018) established a vibration reduction model of radial vibration caused by an unbalanced force of the high-precision spindle, and proved by numerical simulation that the amplitude of the spindle at working speed can be minimized by optimizing shaft diameter, bearing damping and stiffness. Zhu et al., (2020) taking the surface normal vibration as the research object, the discrete element method was used to simulate the simplified granular chute flow, and the influence of vibration on landslide runoff was discussed. Lounis et al., (2017) used the $\mathrm{H} / \mathrm{V}$ environmental vibration method to divide the El Achour landslide, completed the determination of the extensive range of the unstable area and the depth of the sliding surface, and tested the effectiveness of the method. The exploration and application of this method are an important practice for the study of vibration monitoring.

The soft rock slope has a certain particularity and in the process of long-term excavation, along with ensuring safe production there is a need to install a number of surface monitoring equipment in order to record data of surface displacement and monitoring of early warning and forecast (Ghasemi et al., 2010). Blasting vibration caused by surface deformation will cause interference to the surface displacement monitoring results which leads to ineffective mechanism in solving the problem. More focused on the existing research results of soft rock slope stability analysis theory and measures, along with time of analysis of converted vibration load into static stress processing (Hack et al., 2007), it is difficult to restore the vibration in the process of slope stress state and deformation law. The main reason for the above problems is that it is difficult to accurately measure and continuously record the stress information generated in the process of vibration, because it requires the help of advanced sensor system for high-precision and fast data acquisition. After collecting the real-time vibration data, it is necessary to use advanced numerical simulation software to convert the vibration data into loads and add them to the numerical analysis model to realize the real-time stability analysis of the slope under continuous vibration conditions. The key technology of vibration monitoring and stability analysis is the design of monitoring system, the construction of the transmission circuit and the acquisition of monitoring data signal. Therefore, the core content of this study is consistent with the theme of the International Journal of circuits, systems and signal processing, and can increase the achievements and influence of this journal in the field of engineering.

In this paper, blasting vibration stress is the main research objective, analyses the main stress components of slope deformation and instability, at the same time through field monitoring and numerical simulation technology to study the deformation law of soft rock slope, revealing the soft rock slope under blasting vibration in the complex stress deformation law. For soft rock pit deformation control and the paper provide technical support for structural optimization.

\section{METHOD BLASTING VIBRATION INDUCED DAMAGE POWER AND SLOPE DEFORMATION RULE}

\section{A. Slope Stability Deformation Power Source Analyses}

There are many factors affecting slope stability, which can be divided into internal factors and external factors according to their sources. Among them, the internal factors include: rock and soil properties, geological structure and rock mass structure, in-situ stress and so on. The properties of rocks and soil mass are the fundamental factors to determine the anti-sliding force of slope, mainly including the physical, chemical, mechanical and hydraulic properties of rock and soil. External factors include: water, vibration, slope shape and surface morphology and other factors.

Among these factors, there are many dynamic factors that can lead to slope deformation, including in-situ stress, water, vibration and so on. These factors can produce dynamic additional loads, as shown in Fig. 1. The in-situ stress originally exists in the intact rock mass in the equilibrium state. Because the excavation destroys the integrity of the stratum and provides the space for stress release, the in-situ stress imbalance is caused and unloading is carried out on the rock mass and the free face of the slope, resulting in the deformation and failure of the slope. In the process of seepage, water will produce seepage force and drag the slope to deform. The vibration load acting on the rock mass will make the rock mass produce coordinated vibration, but the vibration load acting on the rock mass structural plane will cause the structural plane extension failure and progressive penetration, and then affect the stability of the slope rock mass. 


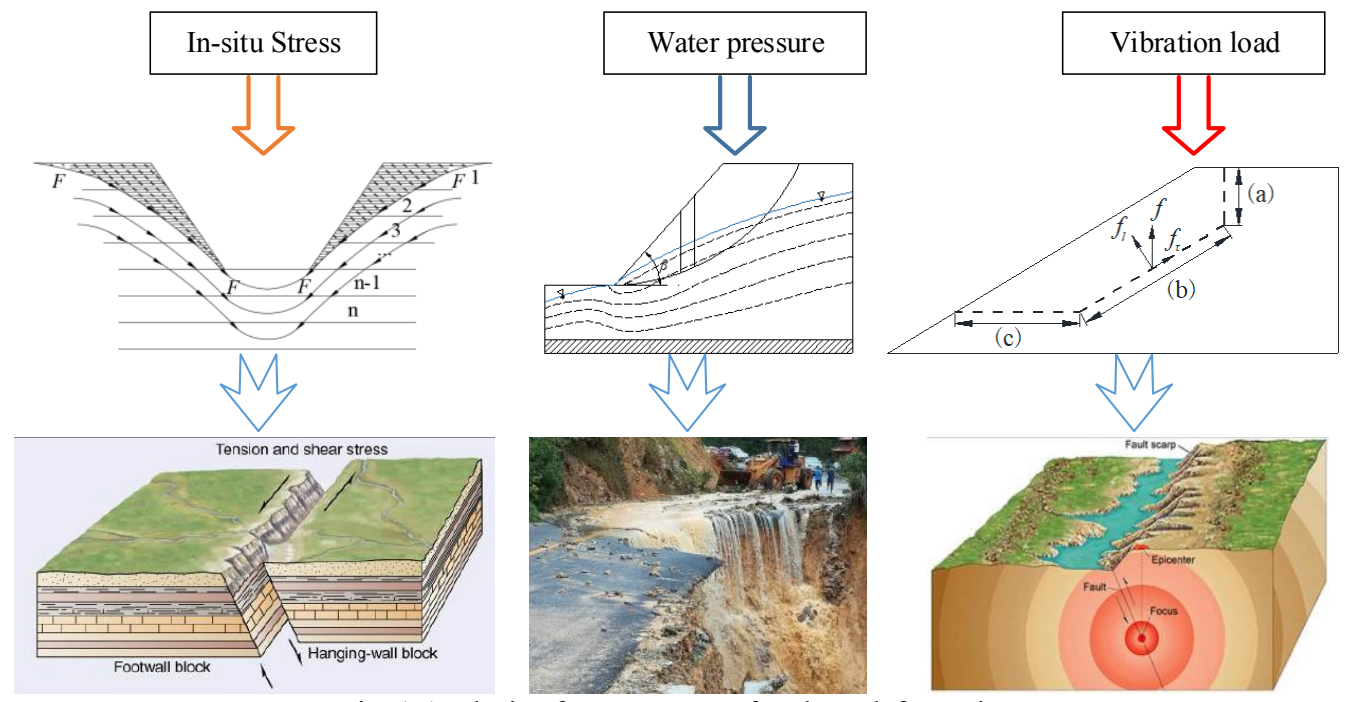

Fig. 1 Analysis of power source for slope deformation

In this paper, the focus of the dynamic stress source is mainly vibration load, in-depth study of the impact of vibration load on slope deformation and stability. The slope deformation power source depends on the external and internal stress induced deformation. The internal stress mainly includes tectonic stress, gravity stress and seismic force while external stress includes blasting stress, dynamic and static loading of equipment, etc. The joint actions of these stresses are similar causing the slope deformation process to be complex, which causes the damage law of the slope deformation to be very difficult to determine.

Mining operations often need to undergo large-scale loose blasting operation. The frequency of vibrations of the rock mass structural integrity and the larger plastic impact on the rheological property of the rock mass can be applied to the stability of the open pit slope. Blasting operation produces particle vibration velocity, and according to Sadaovsk formula said can be determined by

$$
V=K\left[\frac{Q^{\frac{1}{3}}}{R}\right]^{\alpha}
$$

From the equation above $V$ is the Particle vibration velocity, $\mathrm{m} / \mathrm{s}, K$ is the different blast pattern, geology, and site condition coefficient, $Q$ is explosive quantity, $\mathrm{kg}$. $R$ is the gauging point to the center of the blast source, $\mathrm{m}$.

The blasting process with the huge chemical release occurs in a short time of stress waves, transverse wave and longitudinal wave, which pass through the rock mass structure on the surface, prompting the rapid rupture of the structure surface. The blasting vibration with regards to slope instability produces additional stress $N$, such that

$$
N=G a / g
$$

Where, $g$ is the acceleration due to gravity, $\mathrm{m} / \mathrm{s}^{2} ; a$ is the acceleration caused by the blast $\mathrm{m} / \mathrm{s}^{2}$; and $G$ is the weight of the slide, $\mathrm{kN}$.

Converting $N$ to a static force $N_{0}$ we obtained

$$
N_{0}=\gamma N=\gamma G a / g
$$

Where $\gamma$ is the instantaneous shaking force into a static scaling factor, given as 0.25 .

According to experiment and statistical data, the vibration of blasting with regards to the surrounding rock mass element produces acceleration speed $a$. The experimental formula for a is such as

$$
a=0.086 Q^{0.83} R^{-3.5} V_{\mathrm{P}}^{2}
$$

\section{B. Slope deformation cause by blasting stress}

The influence of blasting vibration cause by the explosive will produce chemical energy in the form of vibration wave which spreads around and passes on to the blasting area of the rock mass causing an adverse effect on the structure. Blasting vibration is a mixture of transverse wave and longitudinal wave which define the vibration wave that influences the structure, acting on the rock mass structure on the surface thereby leading to the stress and strain law. On the effects of the transverse longitudinal wave blasting in rock mass the slide body horizontal and vertical load is defined as

$$
\left\{\begin{array}{l}
F_{\mathrm{h}}=\gamma G a_{\mathrm{h}} / g \\
F_{\mathrm{v}}=\gamma G a_{\mathrm{v}} / g
\end{array}\right.
$$

Where $F_{h}, F_{v}$ are the respective blast generated horizontal and vertical loads, $\mathrm{kN}$; ah, av are the horizontal and vertical vibration acceleration, $\mathrm{m} / \mathrm{s}^{2}$.

Blast surrounding rock caused by high frequency vibration produces by two vectors, acceleration and velocity have serious impact on the rock mass. Blasting vibration caused by the coherent speed of the particles in different time can be deduced by means of integral calculation

$$
V_{A-B}=\int_{t_{A}}^{t_{B}}\left[a_{i}-a_{\mathrm{o}}\right] \mathrm{d} t
$$

In $\left[t_{A}, t_{B}\right]$ time interval, the vibration causes the accumulative displacement such as

$$
S_{A-B}=\int_{t_{A}}^{t_{B}}\left[V_{B}-V_{A}\right] \mathrm{d} t
$$

Long-term field observation and theoretical research show 
that the size of the total amount of displacement is not only related to the intensity of the vibration, which are also associated with the vibration frequency. Blasting mode selection, the determination of parameters mainly depends on the soundness of the rock, rock structure, a crack in the rock joints, weathering degree, types of explosive, The diameter of the charge, charge mode, blasting parameters, number of free surface and degree requirements, etc. The vibration process will cause the slope deformation due to the rapid degradation of the rock mass structural strength. With the increase of the test and the hole center distance, a negative exponent decreasing

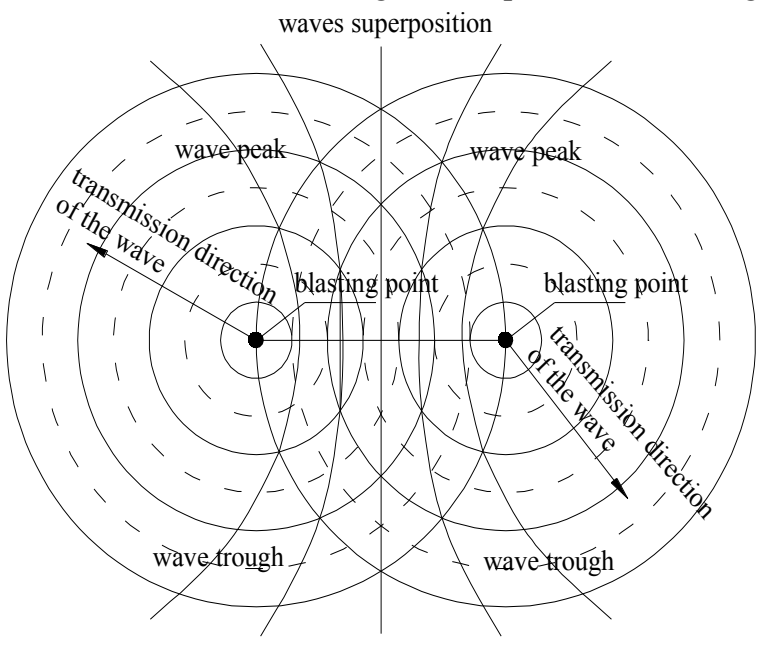

(a) Blasting vibration stress wave vibration acceleration is obtained. This is caused by the transverse and longitudinal stress wave of blasting of rock mass which deform, fracture and breakup by the main power source. The close distance from the blasting center, the more the breakage degree. At the two coherent focus line center there is the axis of symmetry, which is the vibration wave superposition position. In addition, when the target point and the difference between the two focal distances to the vibration wavelength $\lambda$ is a multiples integers, the vibration affects the strength.

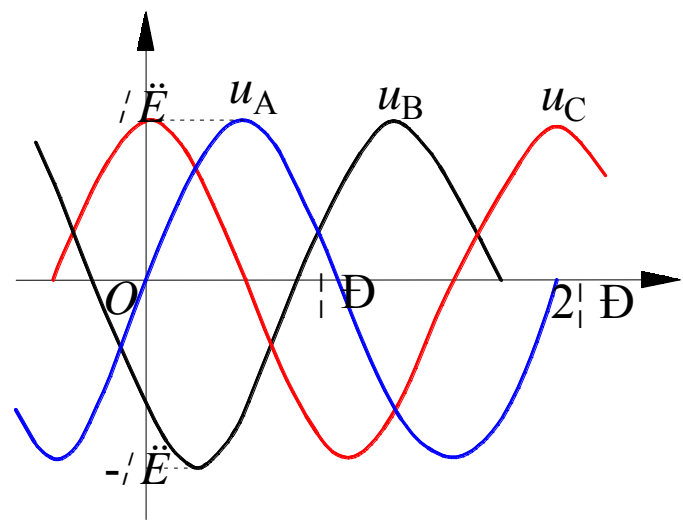

(b) Stress wave superposition structure

Fig. 2. Transmission and superposition model of blasting vibration stress wave

From Fig. 2, the blasting characteristics of the different vibration stress wave in the rock mass transfer, stacked, and each break point generates the vibration wave $u_{A}, u_{B}, u_{C}$ as shown in the vibration curve. When different vibration wave is in the same location, the peak time, will appear with more significant effects. In open-pit mine blasting operation, can be obtained through field monitoring and simulation analysis of slope deformation of key areas. At this time, there will be some errors between the field monitoring data and the simulation analysis data, because the field monitoring data are the superposition result of the displacement data caused by the gravity of the rock and soil and the displacement data caused by the vibration. This data is difficult to be effectively split according to the above two causes, which makes it difficult for subsequent slope deformation analysis. Therefore, according to the monitoring data of vibration stress wave, the slope deformation law caused by vibration is simulated and analyzed. It can not only accurately measure the influence of blasting on slope deformation, but also eliminate the error interference caused by vibration on slope surface monitoring displacement from the measured data of slope displacement.

\section{BLAST DEFORMATION INFLUENCE ON THE GANGUE SLOPE OF LIJIAHAO COAL MINE}

\section{A. Geologic Aspect}

Lijiahao Minefield is located in Dongsheng District, Erdos City, Inner Mongolia Autonomous Region, as shown in Fig. 3. The geographical coordinates of the center are $110^{\circ} 1^{\prime} 33^{\prime \prime}$ east longitude and $39^{\circ} 43^{\prime} 58^{\prime \prime}$ north latitude, as shown in Fig. 2. The topography of the mining area is generally high in the north and east, low in the south and west. The general elevation range is $+1500 \sim 1430 \mathrm{~m}$, and the relative height difference is about $70 \mathrm{~m}$. The mining area is a continental climate with a temperate plateau in the arid desert. The precipitation is small and the evaporation is large. The annual precipitation is $194.7 \sim 531.6 \mathrm{~mm}$, and the evaporation is $2297.4 \sim 2833 \mathrm{~mm}$. 


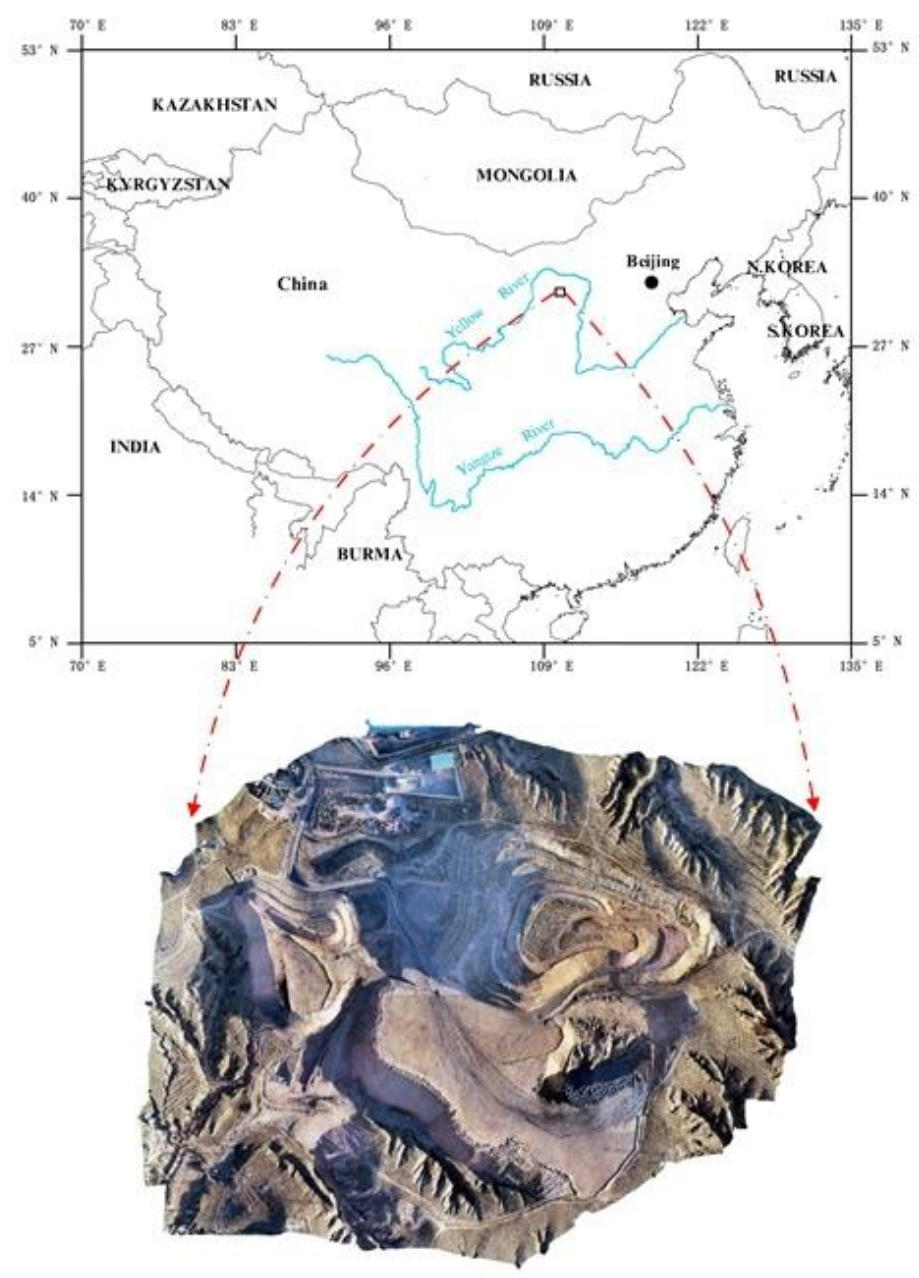

Fig. 3 Location of the study area

The Lijiahao Coal Mine is located $400 \mathrm{~m}$ south of the Industrial Square, covering an area of 30.2 hectares. The current area is $34,683 \mathrm{~m} 2$. The height difference between the highest point of the Gangue Mountain and the Industrial Square is about $82 \mathrm{~m}$. The valleys under the Gangue Mountain are seasonal valleys, with no surface runoff in perennial and surface runoff in summer and autumn. The area is a weak earthquake zone prediction range, and the seismic fortification intensity is 7 degrees. There is no record of destructive earthquakes in history. Therefore, the impact of earthquakes is not considered when evaluating the deformation law of the meteorite slope.

The coal bearing strata in Lijiahao minefield are Jurassic system, the average thickness of mineable coal seams is $3.86 \mathrm{~m}$ and $4.707 \mathrm{~m}$, the roof lithology of each mineable coal seam is mostly sandy mudstone and siltstone, and some parts are fine-grained sandstone; the floor is sandy mudstone. The coal seam depth of the first mining panel is about $200 \mathrm{~m}$. The designed production capacity of lijiahao mine is $6.00 \mathrm{Mt} / \mathrm{a}$ and the service life is $63.3 \mathrm{a}$. The design determines to adopt the long wall type comprehensive mechanized coal mining method, one-time mining full height mining technology.

The gangue generated in the mining process is directly transported to the waste dump by the auxiliary shaft with rubber tyred truck. The gangue extracted from the coal mine is not only from the coal seam gangue, but also from the direct roof and roadway excavation along with the coal mining face collapse. The roof and floor of the coal seam extracted with the working face have become an important source of mine gangue. Since the establishment of the mine, Lijiahao coal mine first dumped the gangue in the valley on the south side of the industrial square; with the advance of mining engineering, the cumulative amount of gangue was gradually increased, and the dumping mode was changed from "filling ditch" to "orogeny". The relative position of gangue dump and industrial square is shown in Fig. 3. Truck transport the gangue from the gangue bin of the industrial square to the gangue dump, and dump the gangue layer by layer by the way of bench edge dumping. Most of the materials roll down under the action of self weight, and a small amount of materials is pushed down by bulldozers. In order to prevent spontaneous combustion of coal gangue, a layer of loess is laid on the top of each step. In order to prevent and control soil erosion and ecological restoration, a thick layer of loess is laid on the top step and slope surface, and reclamation is carried out in time. 


\section{B. Blast Vibration data collection}

Since 2017, with the increasing stacking height of the gangue mountain, the stability problem of the slope has become increasingly severe, and the frequent blasting disturbance during the mining process has caused the deformation cracks of different scales on the top of the meteorite mountain as shown in Fig. 4. The fracture starts from the north side of the flat plate at the top of the gangue dump, and gradually extends to the South and West, and finally intersects with the western side. The total length of the cracks is more than $15 \mathrm{~m}$, and the maximum width is $2 \mathrm{~cm}$. An independent area is circled at the top of the gangue dump. The whole area is towards the free face of the Shanxi side slope of the gangue, which has an obvious sliding trend. In order to evaluate the influence of slope deformation on safety production, a monitoring line is selected on the Shanxi side slope of gangue, and two monitoring points are arranged on the monitoring line to collect and record the vibration signal. The principle of monitoring line layout includes four aspects:

(1) From top to bottom, it runs through the Shanxi slope of gangue,

(2) The extension direction of the monitoring line coincides with the axis of the tensile crack on the upper part of the step, (3) The west slope is the highest position of the whole waste dump,

(4) The foot of the west slope is the closest to the material storage warehouse of the industrial square, and the linear distance is less than $20 \mathrm{~m}$.

The two monitoring points are respectively installed on the flat plate of the second step and the lowest step of the western slope. Combining with the vibration data monitored on site and the slope model to simulate the deformation, to reveal the influence law of vibration load on slope deformation.
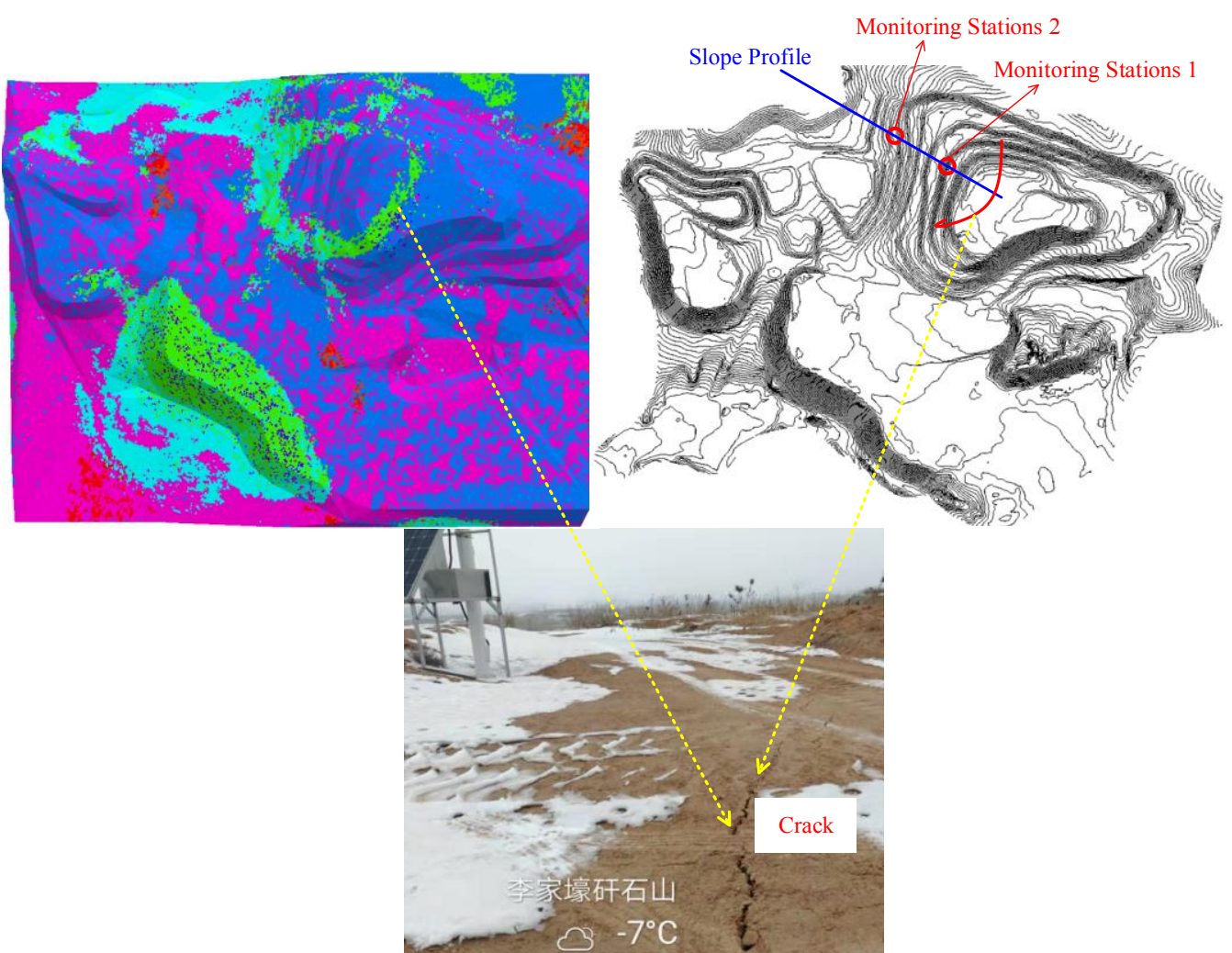

Fig. 4 Vibration monitoring scheme of gangue slope

In order to analyze different blasting methods on the deformation law of the gangue slope of Lijiahao Coal Mine, this research adopts the UBOX - 20016 vibration signal recorder (Fig. 5a) in order to gather the process of blasting vibration waveform. The instrument starts to record about 1 min before the blasting, and continuously records to $1 \mathrm{~min}$ after the complete blasting. All vibration displacement information within this time range is obtained, and the data is saved in the memory card in the form of TXT text. After the vibration data collection, the data is exported, and the data before and after blasting are deleted, and only the vibration data of blasting stage are retained. Plot these data into curves, as shown in Fig. 5 b. 

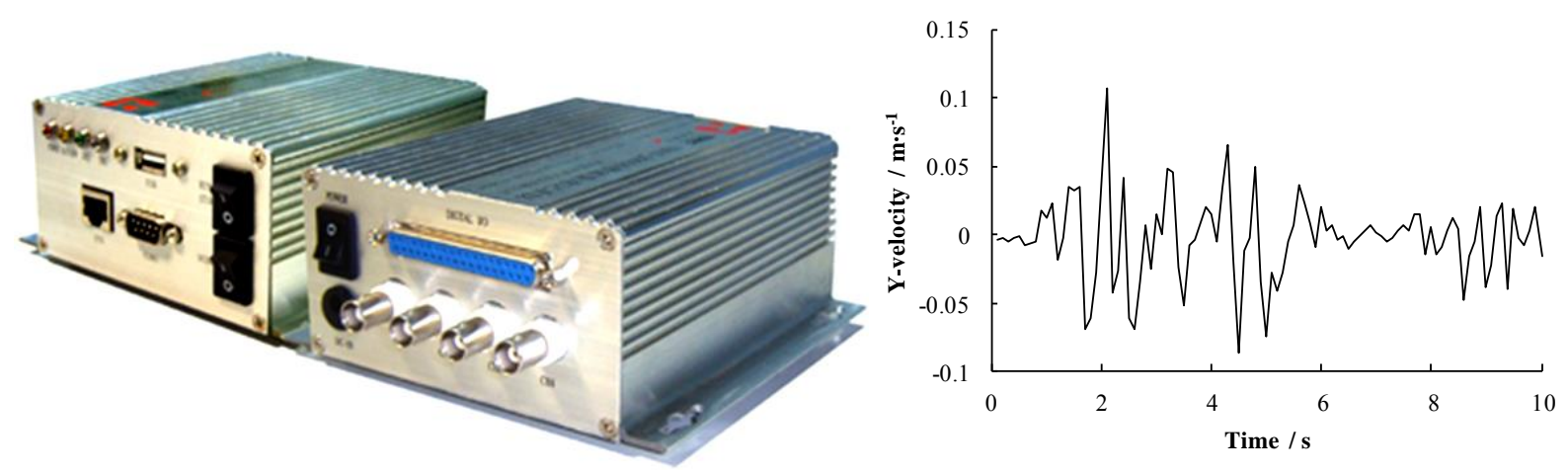

(a) UBOX-20016 vibration signal recorder

(b) Blasting vibration velocity duration curve

Fig. 5 Blasting vibration monitoring equipment and data

\section{Blast vibration model analysis}

Two dimensional section is drawn along the vibration monitoring line, then a representative section is selected for the highest position of the gangue slope, which is perpendicular to the main deformation zone of the meteorite. According to the basic construction plan of the waste rock mountain, the steps are piled up and covered with $1 \mathrm{~m}$ thick loess on each step reaching the stacking height, thus forming a unique slope stratum structure of the Gangue Mountain at Lijiahao Coal Mine. At the slope in Fig. 6 two monitoring stations were selected to ensure the two vertical slope monitoring point.

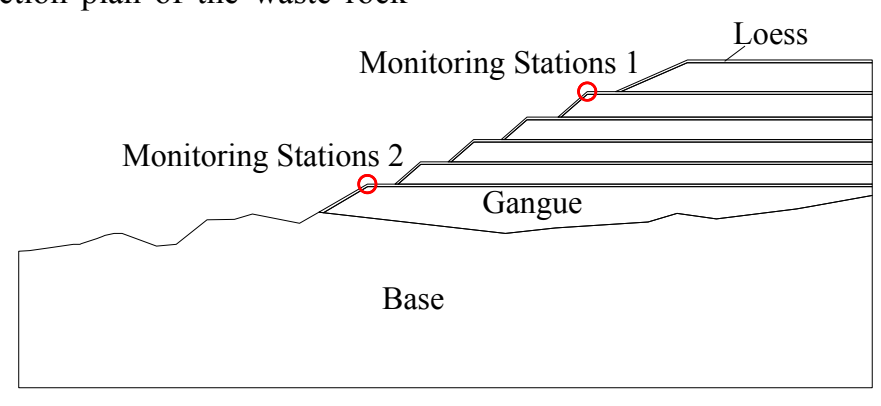

Fig. 5 Vibration displacement monitoring points in the west slope

Blasting vibration not only give rise to the change of the factor of safety, but also the deformation undulation. GEO-studio was adopted to analyze the slope initial stress, and then the vibration waveform was inputted in the QUAKE/W module. The vibration waves were collected using the instrument in Fig. $5 \mathrm{~b}$ as Fig. 6 shows the two monitoring stations on the slope where the record of the blasting vibration load for the displacement of the slope was obtained.

GeoStudio is a professional, efficient and powerful simulation software for geological engineering and geological environment simulation calculation. GeoStudio, as an excellent geological engineering design and analysis software, has provided incomparable help for millions of scientific researchers, engineers, educators and students. This software includes eight kinds of professional analysis software, among which quakegwas one of them. It can carry out horizontal and vertical coupling dynamic response analysis of linear and nonlinear soil, and obtain the real-time stress state of the slope under the influence of seismic load. At the bottom of the slope model on the right side in a position of $20 \mathrm{~m}$, a vibration velocity waveform was entered into the model obtaining two displacement monitoring data as shown in Fig. 7, and Fig. 8. 

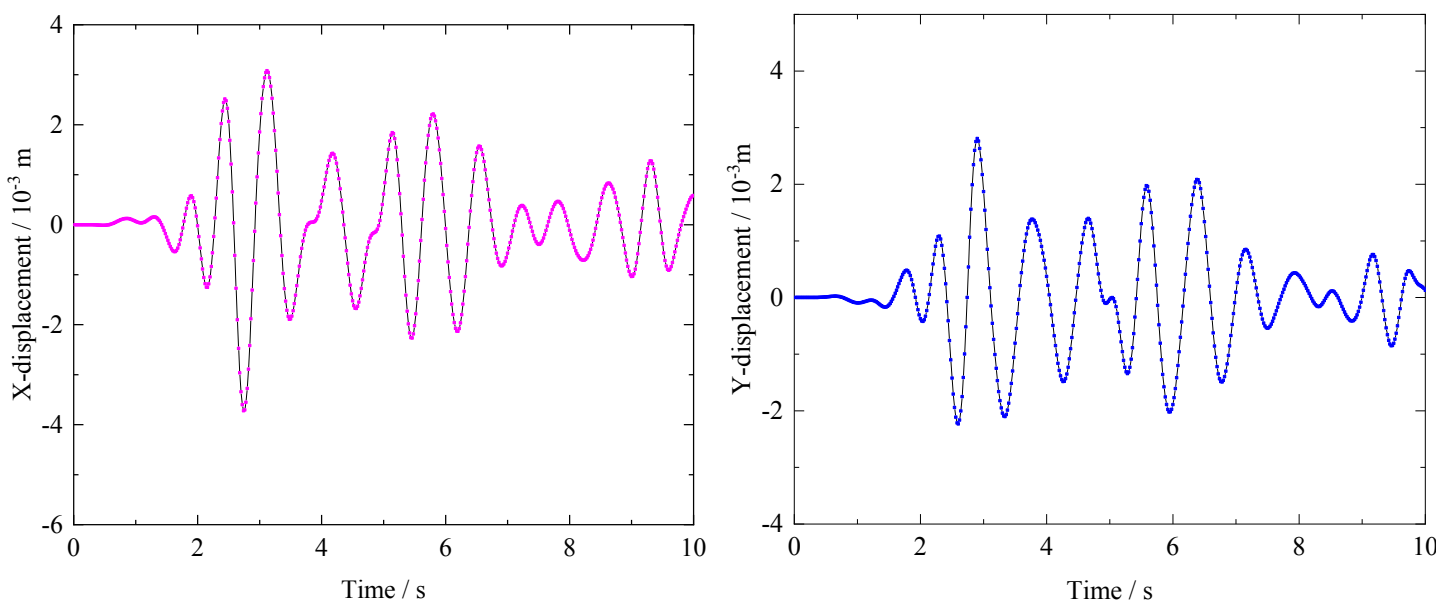

Fig. 7 The history displacement data of monitoring point 1
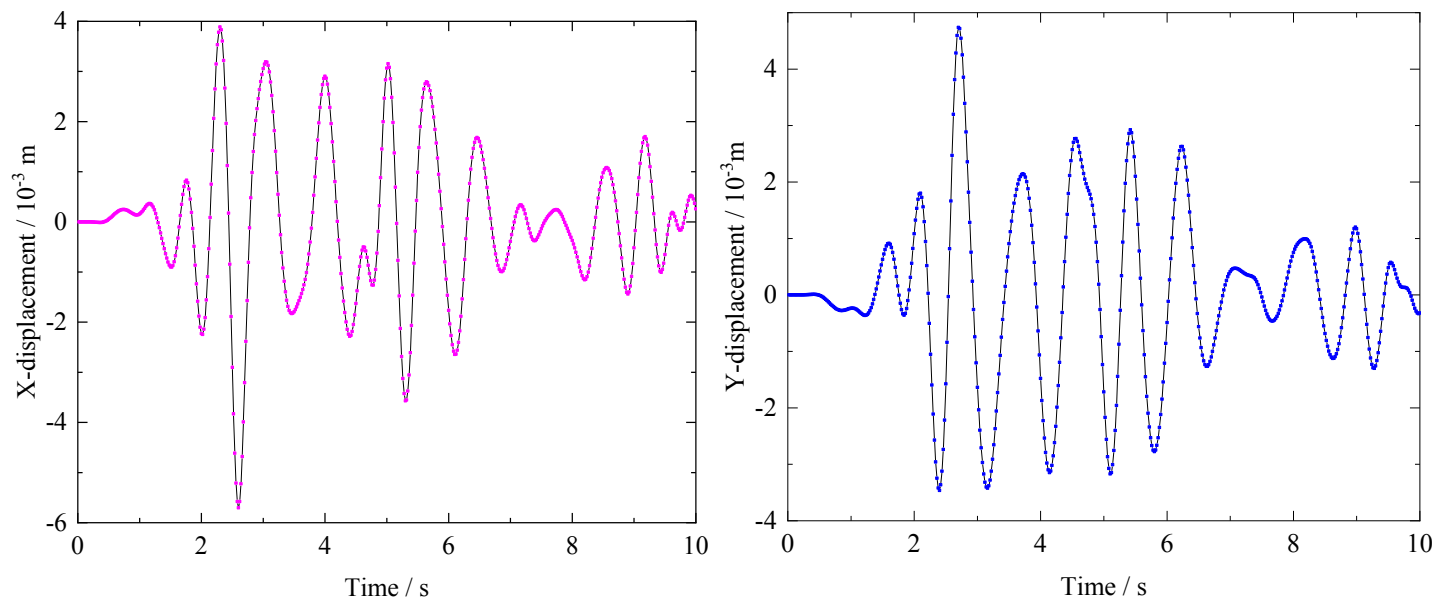

Fig. 7 The history displacement data of monitoring point 2

Monitoring stations 1 had a blasting source distance of 250 $\mathrm{m}$, while monitoring station 2 had a blasting source distance of 140 m. From Fig. 7 and Fig. 8 it can be seen, that monitoring station $2 \mathrm{X}$ and $\mathrm{Y}$ displacement historical fluctuates significantly higher than that of monitoring stations 1 . The peak displacement of monitoring station 2 is higher than that of monitoring point 1 . The peak displacements in $\mathrm{X}$ and $\mathrm{Y}$ directions of monitoring point 1 and monitoring point 2 as well as their occurrence time, as well as the final time displacement in $\mathrm{X}$ and $\mathrm{Y}$ direction are counted, as shown in Tab. 1. Compared with monitoring point 1 , the peak displacement of monitoring point 2 is $26.16 \%$ higher than that of monitoring point 1, and the peak displacement of $\mathrm{Y}$ direction is $68.82 \%$ higher than that of monitoring point 1 . At the final moment, the displacement in $\mathrm{X}$ direction of the two monitoring points is close, but the displacement in $\mathrm{Y}$ direction is quite different. At the final moment, the y-direction displacement of monitoring point 1 is positive, while that of monitoring point 2 is negative, that is, "uplift" of monitoring point 1 and "settlement" of monitoring point 2 . The two groups of the distance monitoring data reflect the break point and monitoring points distance is one of the important factors influencing the slope deformation and displacement.

Tab. 1 statistical data of peak displacement and final time displacement of monitoring points

\begin{tabular}{|c|c|c|c|c|c|c|}
\hline \multirow{2}{*}{ monitoring point } & \multicolumn{3}{|c|}{ Peak displacement and time } & \multicolumn{2}{c|}{ Final displacement } \\
\cline { 2 - 7 } & $\mathrm{X}$ & time / s & $\mathrm{Y}$ & time / s & $\mathrm{X}$ & $\mathrm{Y}$ \\
\hline Monitoring point 1 & 0.003080263 & 3.12 & 0.002806767 & 2.9 & 0.00058464 & 0.000128642 \\
\hline Monitoring point 2 & 0.003885923 & 2.3 & 0.00473845 & 2.7 & 0.00025804 & -0.0003202 \\
\hline
\end{tabular}




\section{INFLUENCE OF BLASTING POSITION AND PARAMETERS ON SLOPE DEFORMATION}

The Simulation study has fully proven that blasting vibration can cause different degrees of deformation on the slope surface. The deformation extent, peak and dip value are presented along with the blasting vibration generated vibration velocity which is very much consistent. The work also shows that blasting vibration is one of the main external sources of slope deformation meanwhile the result also shows that the slope deformation and vibration waveform is collaborative. The Slope monitoring point deformation is associated with the blasting center distance, which is the closer the distance the greater the displacement produce. Open-pit mine blasting has a complicated pattern, numerous snap point, ways of initiation has its own difference, number of explosive sources are different, initiation time difference all has varying degree of influence with regards to the monitoring point of slope deformation. This research discusses the influence of the

explosion source distance and the slope deformation initiation time.

A. Relationship between the Focal distance, vibration displacements

At the gangue dump slope bottom plate according to the center of the explosion source, origin, $10 \mathrm{~m}$ in the stope layout is the first monitoring point and then after every $40 \mathrm{~m}$ intervals a monitoring point is installed, totaling five monitoring stations. Analytical results obtained from the five displacement monitoring data of the final moments of the $\mathrm{X}, \mathrm{Y}$ is shown in Fig. 9.

On the flat plate at the bottom of the slope, $50 \mathrm{~m}$ away from the bottom line of the lowest step slope is taken as the focal center, and the first monitoring point is arranged by extending $10 \mathrm{~m}$ to the west side slope of gangue, and then one monitoring point is arranged every $40 \mathrm{~m}$, totally 5 monitoring points are arranged. Establish the slope vibration analysis model, input the vibration signal at the focal point, analyze and get the displacement data of 5 monitoring points, and get the final moment of vibration end, the $\mathrm{X}$ and $\mathrm{Y}$ direction displacement of 5 monitoring points are shown in Tab. 2.

Tab. 2 The displacement data at final moments of each monitoring points

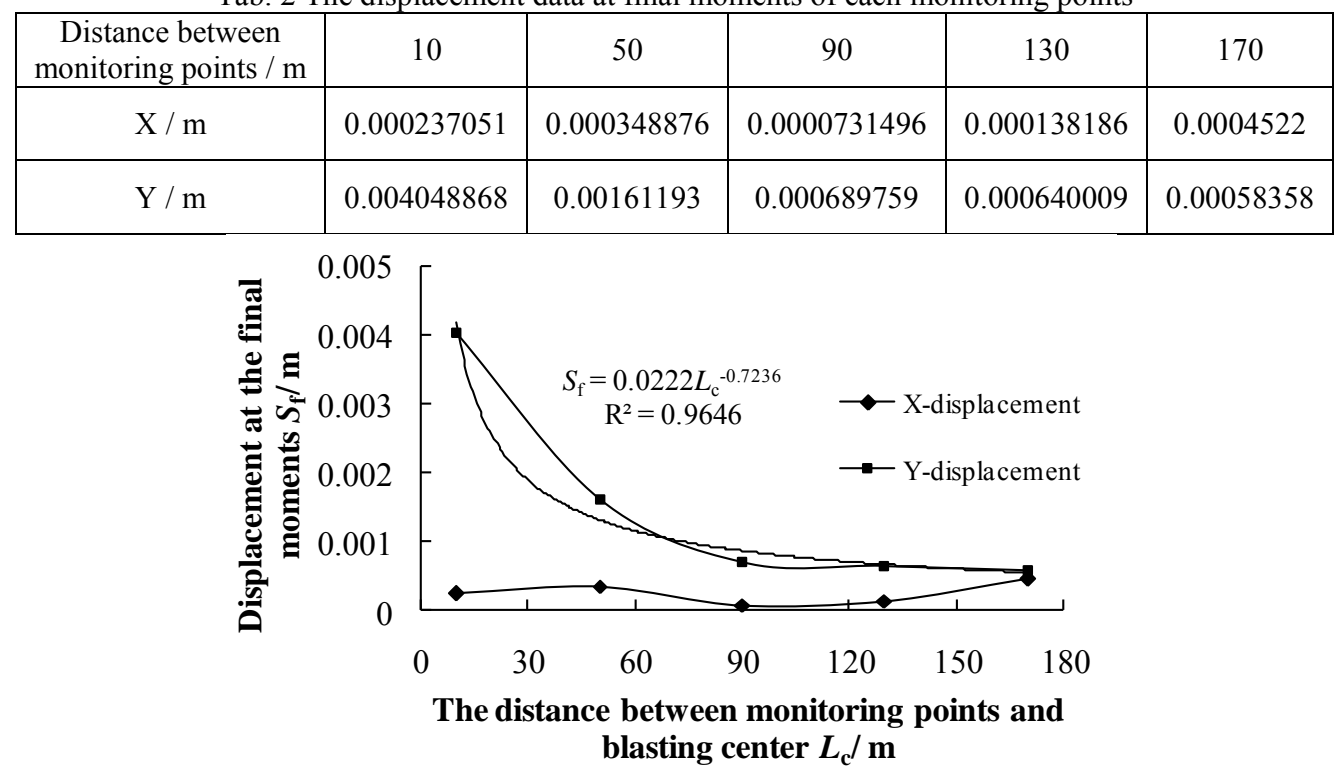

Fig. 9 The displacement curve of each monitoring points on $\mathrm{X}$ and $\mathrm{Y}$ direction at final moment

According to the displacement statistical data, the displacement change curves in $\mathrm{X}$ and $\mathrm{Y}$ directions of 5 monitoring points are drawn, as shown in Fig. 9, the $\mathrm{X}$ direction displacement under the influence of blasting vibration is small and the result did not show any obvious law of development. For the Y direction displacement decreases continuously with the increase of the distance between the monitoring point and the blasting center. The regression analysis shows that the $\mathrm{Y}$ direction displacement $S_{\mathrm{f}}$ at the final moment and the distance $L_{\mathrm{c}}$ from the blasting source center satisfy the logarithmic functional relationship $\mathrm{Sf}=0.0222 \mathrm{Lc}-0.7236(\mathrm{R} 2=0.9646)$. From the regression function, it can be seen, following the monitoring point and the distance from the center of explosive source Lc constantly increases. In the Y displacement direction of Sf, the power function law gradually declines, constantly tend to the limit value 0 . This means that when the monitoring points and the center is far enough from an explosive source, blasting vibration influence on the structure of slope deformation can be ignored, this also accords with the common law of blasting damage.

B. Multipoint simultaneous vibration of the $Y$ direction displacement

In addition to the slope surface monitoring points undulation displacement and the distances from the break point there is a relationship between them and also there is a relationship between the number of explosive source and the 
initiation pattern factors. Based on the control variate research method, the design of different numbers of shot point, spacing arrangement, initiation time were analyzed under different conditions of displacement monitoring data which reveals the
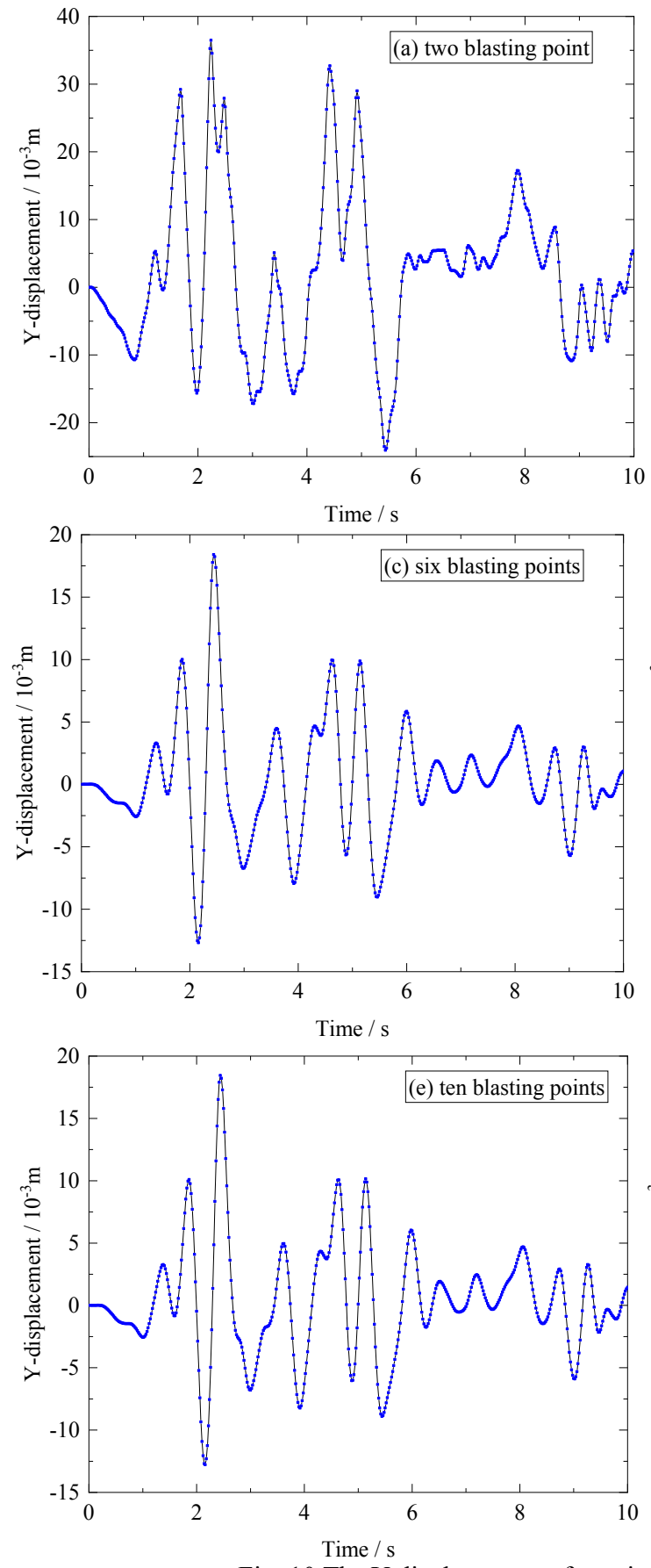

Fig. 10 The Y-displacement of monitoring point 1 with multipoint blasting

Different statistical number of shot points in the final moments of monitoring station 1 and monitoring station 2 influence law of slope stability of multi-point vibration load. Fig. 10 shows the results of the different shot point displacement.
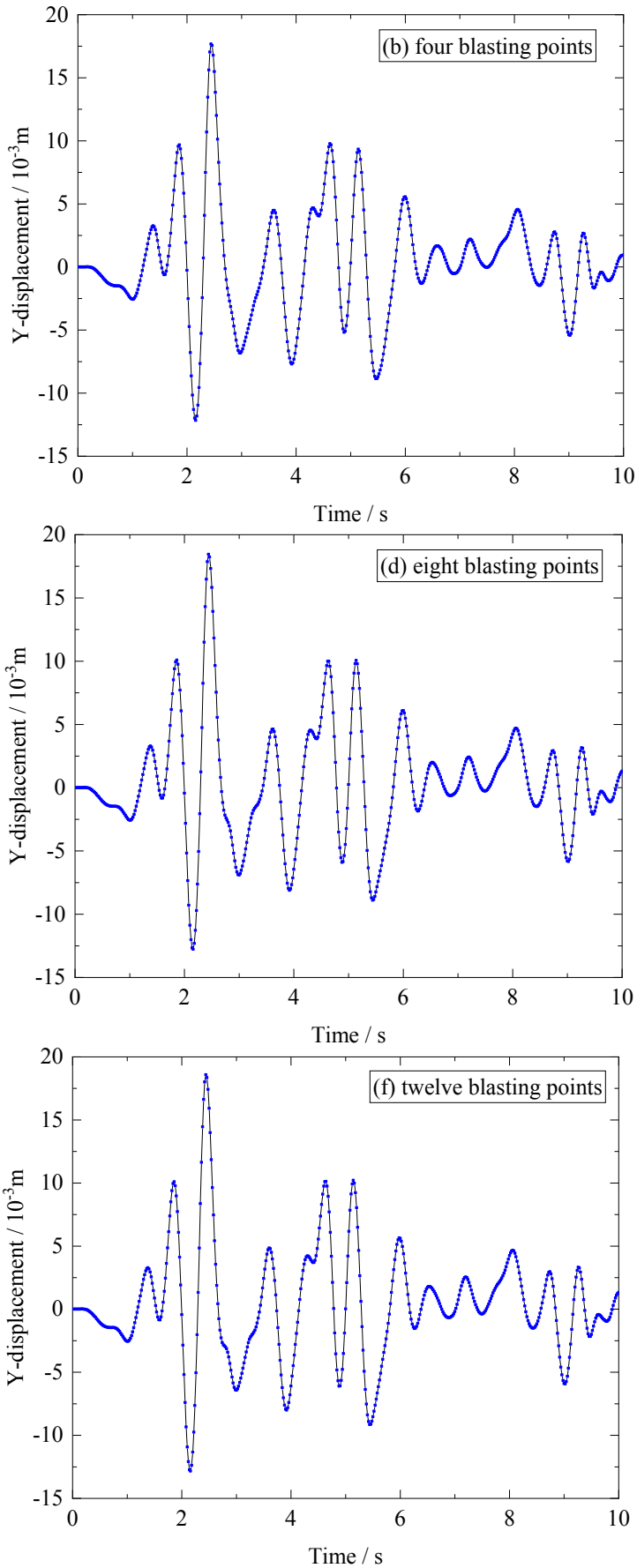

shows the Y direction displacement data curve in Fig. 11. 


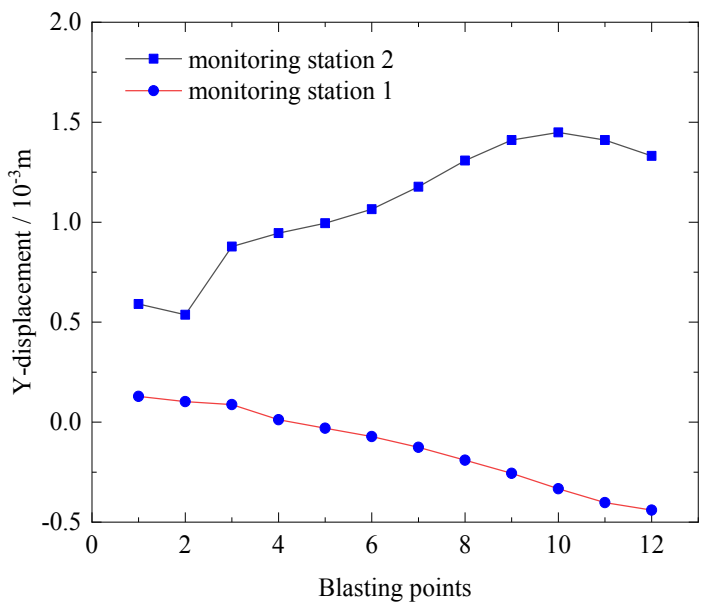

Fig. 11 The relation curve of blasting points and Y-displacement at ultimate moment

As can be seen from Fig. 11, as the number of shot points increases, the slope surface monitoring point final moment in the $\mathrm{Y}$ displacement direction takes an increasing trend. That is to say the more shot point give rise to the slope deformation and the greater the displacement of the rock mass. However the specific deformation situation and displacement development rule depend on the location of the monitoring points and the combination of vibration stress and the rock mass gravity. Monitoring point 1 at the slope crest is influenced by vibration stress and slide occur at the main deformation direction along the slope trend. Monitoring point 2 is closer to the shot point, has a lower height and is under the vibration stress and the extrusion of the surrounding rock mass where the deformation appears as "bulking" and is the main deformation pattern. Hence, when a large-scale blasting

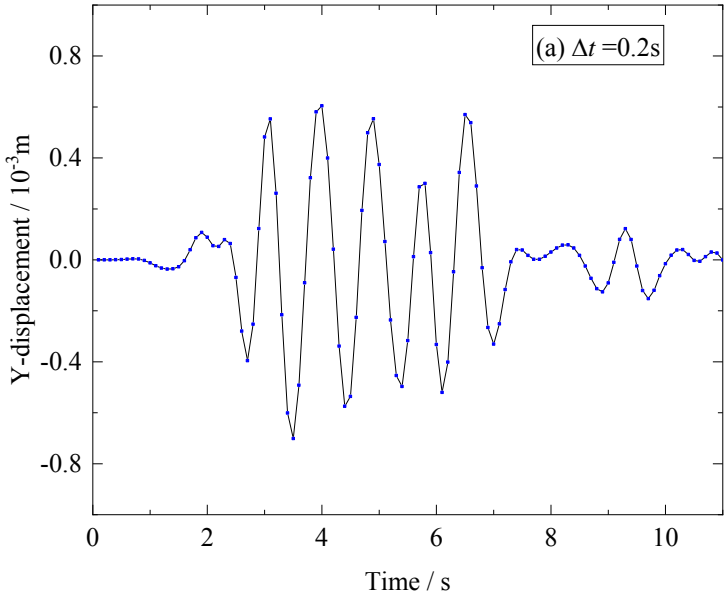

occurred nearby the gangue slope, the suitable operations should base on the slope form and specific location the adoption of a corresponding control measures in order to avoid the induces engineering disasters of blasting operation.

\section{Multipoint Non-simultaneous Vibration of the $Y$} Direction Displacement

The shot point number has direct influence on the slope deformation as there exist a relationship between the initiation time and the slope deformation. Using 5 point blasting according to a different time interval of blasting vibration simulation, the research obtains the different monitoring point historical displacement monitoring data as shown in Fig. 12 and Fig. 13.

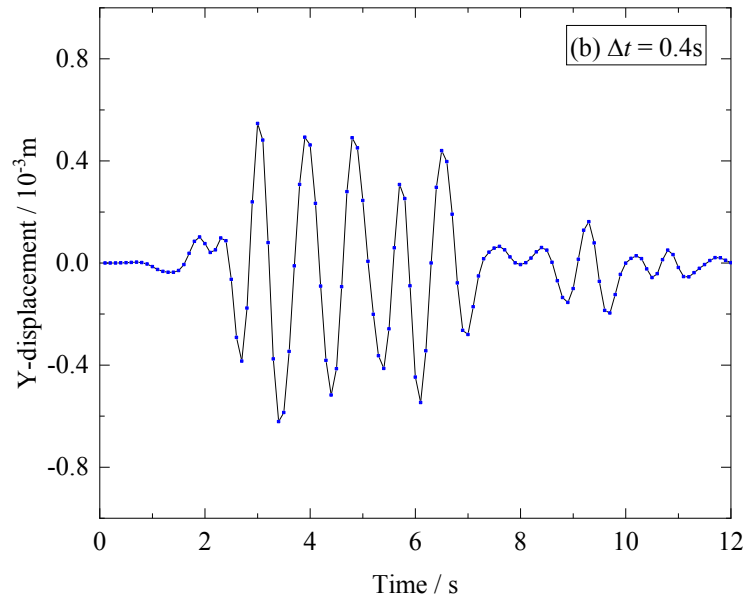


NTERNATIONAL JOURNAL OF CIRCUITS, SYSTEMS AND SIGNAL PROCESSING
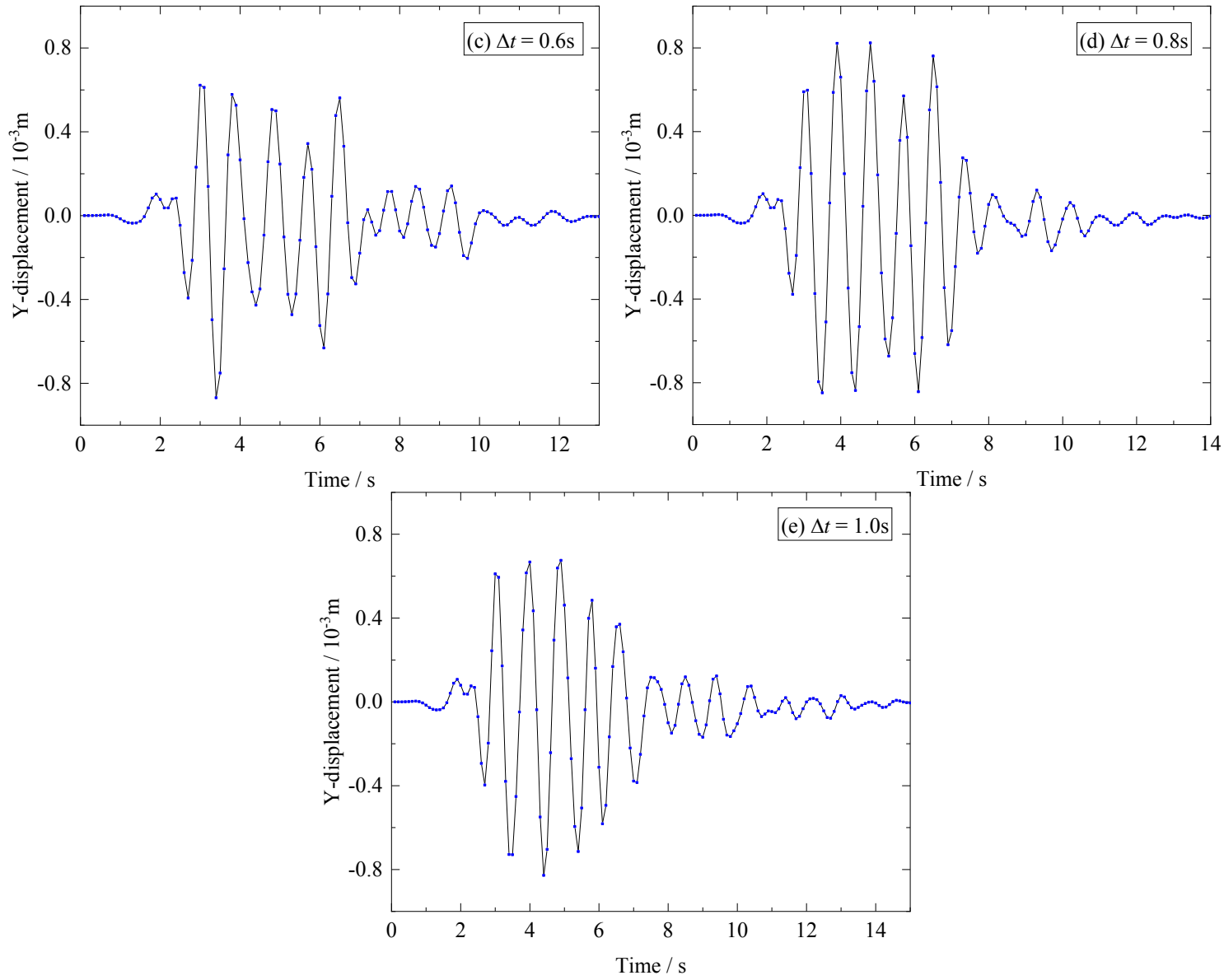

Fig. 12 The history displacement of monitoring point 1 under different time difference
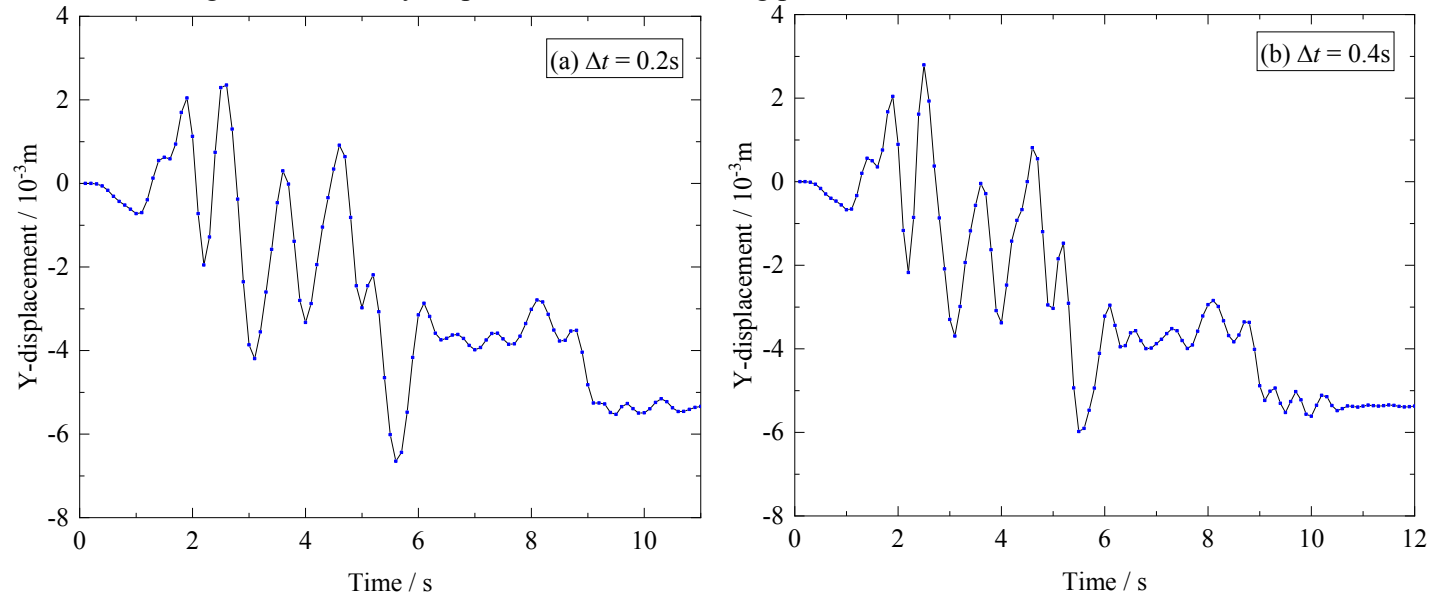


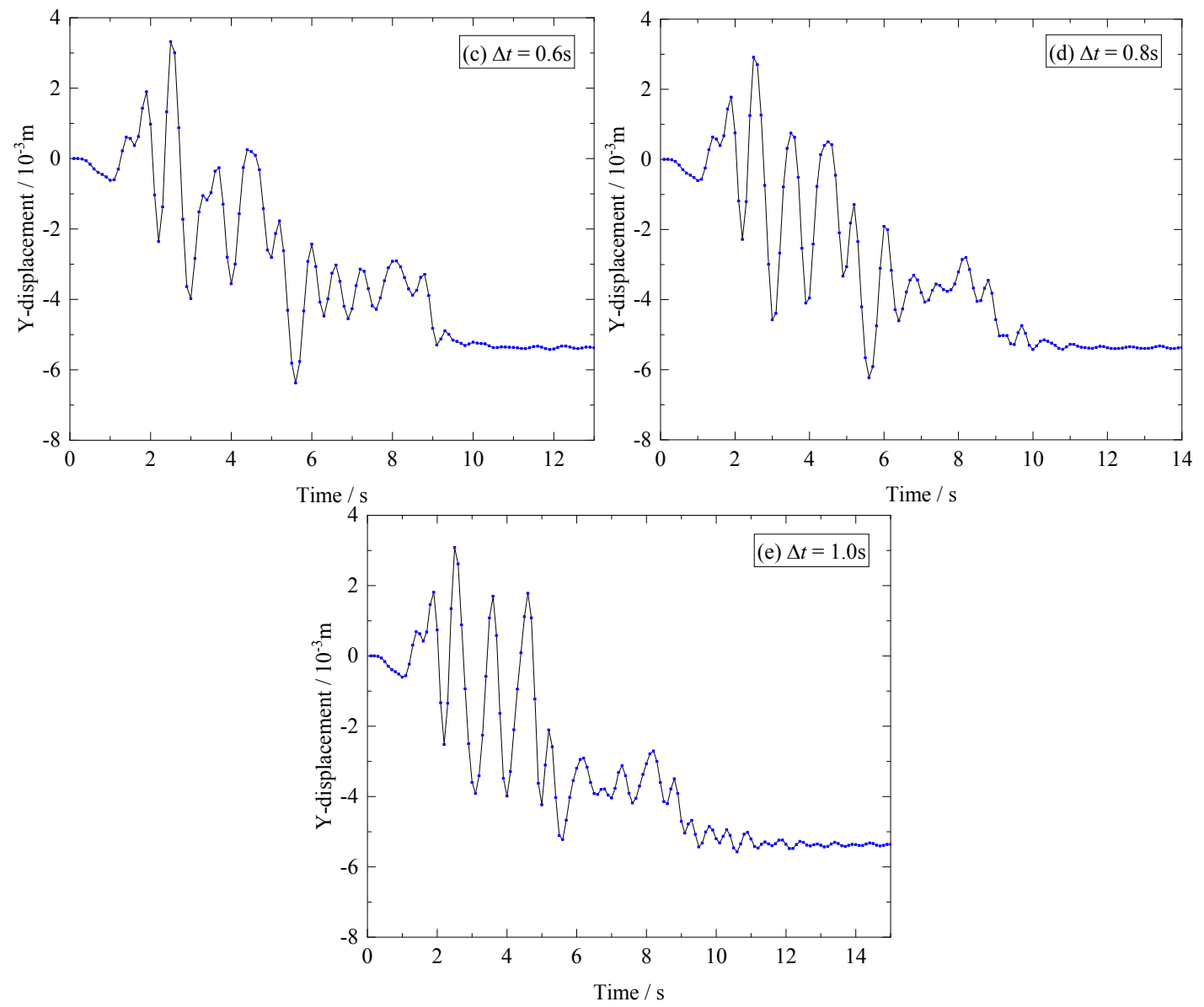

Fig. 13 The history, displacement of monitoring point 2 under different time difference

Fig. 12 and Fig. 13 reflect the fluctuation difference in the curve of the blasting vibration on the slope displacement caused by different positions. Based on the two monitoring points Tab. 3 shows the statistical final moment of the two monitoring points historical monitoring displacement data.

Tab. 3 The Y-displacement of each monitoring point under different time difference

\begin{tabular}{|l|l|l|l|l|l|}
\hline Time difference & 0.2 & 0.4 & 0.6 & 0.8 & 1.0 \\
\hline Displacement of monitoring station $1 / 10^{-7} \mathrm{~m}$ & -6.23 & 11.2 & -44.2 & -47.7 & -49.9 \\
\hline Displacement of monitoring station $2 / 10^{-3} \mathrm{~m}$ & -5.3371 & -5.3706 & -5.3768 & -5.3660 & -5.3578 \\
\hline
\end{tabular}

The five points simultaneous blasting at monitoring station 1 and station 2 forms an ultimate simultaneous displacement of $-3.02 \times 10-5 \mathrm{~m}$ and $9.95 \times 10-4 \mathrm{~m}$ respectively. In Table 1 the displacement caused by non-simultaneous blasting can be compared and discovered. The multipoint non-simultaneous reduces the blasting vibration on monitoring station 1 which causes the slope displacement, but increases at monitoring station $2 \mathrm{Y}$ direction displacement, and changed the main direction of the displacement.

Monitoring points 1 and 2, the final moments of displacement numerical difference is comparatively large on the basic maintaining the 104 orders of magnitude difference. Hence, the closer the distance of multipoint non-simultaneous blasting to the source, the more obvious the stress superimpose effect. With the increasing of the explosive source center distance, the blasting stress gradually attenuates and the stress superimpose effect weakened exponentially. According to the displacement data of the two monitoring stations the results comply with the time interval change rule, known as the blasting time discrepancy increment. The displacement data of monitoring point 1 increases and there exist the limiting displacement. The deformation displacement discrepancy of monitoring station 2 is not many along with the undulating change, but constitute a good relationship with the function of the size of the time difference.

Relative to multipoint simultaneous blasting, multipoint non-simultaneous blasting has a weakening effect on slope deformation. If the initiation time selecting is appropriate, it is an effective validation of the peak and troughs of waves which will overlap in the same position, effectively reducing the 
influence of blasting vibration in the blasting area. This is advantageous to the long-term safety and stability of slopes.

Blasting stress wave produced by the vibration not only causes deformation and displacement of the slope, but produces vibration for rock mass horizontal, vertical and additional stress, which produces the force in the component structure, the reduces the slope stability factor of safety. In the process, the influence of blasting vibration, on the slope stability factor of safety will also appear with the vibration acceleration, continuous undulation which serves as the continuing effects of blasting vibration. The cumulative displacement should exceed the maximum allowable structural surface displacement which obviously decreases the shear strength on the damaged structural plane. Therefore, in the process of blasting vibration the decrease of the slope stability factor of safety, evaluate the slope stability under blasting vibration influence. However, it needs to be fully combined with the deformation degree, structure, surface rupture degree in order to evaluate the effective shear strength of structure, on the basis of vibration stress given the aging stability coefficient of slope, the change rule of this is a problem that need to be further studied. These methods could combined with the methods of [21], 22] and [23].

\section{CONCLUSION}

Through the stress analysis of the blasting process, the horizontal and vertical acceleration along with the additional stress is the main cause of the slope deformation. Based on the acceleration, the process of vibration displacement formula is derived and at the same time the deformation superposition model formation of the vibration source is established. Within the scope of the deformation of gangue slope at the Lijiahao Coal Mine, the vibration signal recorder was used to collect the blasting vibration wave and the simulation analysis was carried out on the displacement monitoring profile, under the influence of blasting vibration as the $\mathrm{X}, \mathrm{Y}$ displacement were obtained respectively. The results show that as the shot point distance increases, the $\mathrm{Y}$ direction displacement forms a decline logarithmic law, while the $\mathrm{X}$ direction displacement variation is very little.

Multipoint simultaneous blasting and more initiating points give rise to greater slope deformation and displacement of the rock mass. If the Multipoint non-simultaneous blasting and detonation time selection is appropriate, it will be effective in reducing the influence of blasting vibration in the blasting area which is advantageous to long-term safety and slope stability.

\section{ACKNOWLEDGMENT}

The paper is the effect of the National Natural Science Foundation of China (No. 51804298 \& No. 51774271).

\section{References}

[1] Gogolewski K., 2007. An algorithm for a certain class of file allocation problems in distributed databases, Proc. 7th Int. Conf. on Systems Eng. Univ. of Nevada, Las Vegas, 424-431.

[2] Sikora Z., 2008. Plasticity of polycrystal, Archives of Mechanics, Vol. 29, No. 5, 687-704.

[3] Finckh L., 1924. Erlauterungen zur Geologische Karte von Preussen, Blatt Charlottenbrunn. Kgl. preuss. geol. L.A. Berlin.

[4] Yang G.L., Yang R.S., Che Y.L., 2013. Damage accumulative effect of surrounding rock under periodic blasting vibration, Journal of China Coal Society, Vol. 38, No. 1, 25-29.

[5] Chang D.S., Zhang L.M., Xu Y., Huang R.Q., 2011. Field testing of erodibility of two landslide dams triggered by the 12May Wenchuan earthquake, Landslides, Vol. 8, No. 3, 321-332.

[6] Chen M., Lu W.B., Shu D.Q., 2009. Calculation method of equivalent acceleration for limit equilibrium analysis of slope under blasting vibration, Chinese Journal of Rock Mechanics and Engineering, Vol. 28, No. 4, 784-790.

[7] Han L., Zhou W., Cai Q.X., Shu J.S., Jing H.W., Li X., 2015. Experimental study on remodeling strength of granular materials under different loads and lengths of time, J. Cent. South Univ., Vol. 22, No. 7 2783-2790.

[8] Han L., Zhou W., Shu J.S., Wang S.W., Meng Q.W., 2014. Plane sliding timeliness stability analysis and structure optimization of soft rock slope, Journal of China University of Mining \& Technology, Vol. 43, No. 3, 395-401.

[9] Exadaktylos G., Stavropoulou M., Xiroudakis G., Broissia M., Schwarz H., 2008. A spatial estimation model for continuous rock mass characterization from the specific energy of a TBM, Rock Mechanics and Rock Engineering, Vol. 41, 797-834.

[10] Gao Y.F., Fan Z.P., 2010. Generalized slice method for stability analysis of slope with non-circular slide face under multipoint and multidirection seismic ground motions, Rock and Soil Mechanics, Vol. 31, No.12, 3816-3822.

[11] Jeremy R., 2014. Dynamic sensitivity analysis of long-running landslide models through basis set expansion and meta-modeling, Nat Hazards, Vol. 73, 5-22.

[12]Wu T., Zhou C., Jiang N., Xia Y., Zhang Y., 2020. Stability analysis for high-steep slope subjected to repeated blasting vibration, Arab J Geosci, Vol. 13, 828-840.

[13]Wu T., Chuanbo Z., Nan J., Xia Y., Zhu B., 2020. Study on the Mechanical Cumulative Damage Model of Slope Fault Fracture Zone under the Cumulative Effect of Blasting Vibration. Period Polytech-Civ, Vol. 63, No. 3, 845- 858.

[14]Yin Y., Zheng W., Li X., Sun P., Li B., 2011. Catastrophic landslides associated with the M8. 0 Wenchuan earthquake. Bull Eng Geol Environ, Vol. 70, No. 1, 15-32.

[15]Fan X., Juang C.H., Wasowski J., Huang R.Q., Xu Q., Scaringi G., Westen C., Havenith H., 2018. What we have learned from the 2008 Wenchuan Earthquake and 
its aftermath: a decade of research and challenges. Eng Geol Vol. 241, 25- 32.

[16] Yoon W.S., Jeong U.J., Kim J.H., 2002. Kinematic analyses for sliding failure of multi-faced rock slopes, Eng Geol, Vol. 67, No. 12, 51-61.

[17] Mihaela C., Martin B., Marta C.J., Marius V., 2011. Landslide susceptibility assessment using the bivariate statistical analysis and the index of entropy in the Sibiciu Basin (Romania), Environ Earth Sci, Vol. 63, 397-406.

[18] Taylor D.W., 1937. Stability of earth slopes, Boston Soc. Civ. Eng., Vol. 24, 197-246.

[19] Hoek. E., Bray J.W., 1977. Rock slope engineering, Institution of Mining and Metallurgy. London.

[20] Alejano L.R., Ferrero A.M., Ramirez-Oyanguren P., Lvarez Fernandez M.I.A., 2011. Comparison of limit-equilibrium, numerical and physical models of wall slope stability, International Journal of Rock Mechanics and Mining Sciences, Vol. 48, 16-26.

[21]Zlatin Zlatev, Methods and Tools for Sensors Information Processing, WSEAS Transactions on Signal Processing, pp. 155-161, Volume 15, 2019

[22] Yong-Song Kim, Tong-Chol Choe, Kum-Hyok Hwang, A Method of Generating Intrinsic Mode Functions through a Filtering Algorithm based on Wavelet Packet Decomposition, WSEAS Transactions on Signal Processing, pp. 162-169, Volume 15, 2019

[23] Luqman Hakim, Muhammad Ihsan Zul, Implementation of Discrete Wavelet Transform on Movement Images and Recognition by Artificial Neural Network Algorithm, WSEAS Transactions on Signal Processing, pp. 149-154, Volume 15, 2019

[24] Chen Z.Y., Shao C.M., 1987. The Use of the Method of optimization for Minimizing Safety Factors in Slope Stability Analysis, Chinese Journal of Geotechnical Engineering, Vol. 10, No. 4, 1-13.

[25] Ronevi G.T., Ronevi B., Skoblar A., Braut S., 2018. Avoidance of numerical singularities in free vibration analysis of Euler-Bernoulli beams using Green functions, WSEAS Transactions on Applied and Theoretical Mechanics, Vol.13, 117-122.

[26] Jauhari K., 2018. Vibration reduction of spindle-bearing system by design optimization, WSEAS Transactions on Applied and Theoretical Mechanics, Vol. 13, 85-91.

[27]Zhu C., Huang Y., Sun J., 2020. Solid-like and liquid-like granular flows on inclined surfaces under vibration Implications for earthquake-induced landslides. Computers and Geotechnics, Vol.123, 1-8.

[28] Lounis G., Mimouni O., Machane D., Bacha A., 2017. The El Achour (Algiers, Algeria) landslide delimitation using the $\mathrm{H} / \mathrm{V}$ ambient vibration method[J]. Arabian Journal of Geosciences, Vol. 10, No.18, 398-407.

[29] Ghasemi E., Shariar K., Sharifzade M., 2010. A new method for risk assessment of pillar recovery operation, Safety Science, Vol. 48, No. 10, 1304-1312.

[30] Hack R., Alkema D., Kruse G.A.M., Leenders N., Luzi L., 2007. Influence of earthquakes on the stability of slopes, Eng Geol, Vol. 91, No. 1, 4-15.

\section{Creative Commons Attribution License 4.0 (Attribution 4.0 International, CC BY 4.0)}

This article is published under the terms of the Creative Commons Attribution License 4.0

https://creativecommons.org/licenses/by/4.0/deed.en_US 